\title{
The real mechanisms of the global economy
}

\author{
ANGEL ASENSIO*
}

The paper presents the main arguments of Bresser Pereira's Globalization and Competition. Development strategies based on the 'conventional orthodoxy' are shown to carry serious drawbacks ("Dutch disease", pernicious effects of external saving, currency overvaluation), while a 'new developmentalism' is promoted, in spite of the widespread belief that the nation-states have been dispossessed of their room for manoeuvre because of the globalization process. The "new developmentalism" is based on domestic finance, balanced public budgets, moderate interest rates and competitiveness policies aimed at neutralizing the tendency to exchange rate overappreciation. The paper also points out a few theoretical questions the book raises.

Keywords: exchange rate; currency overvaluation; growth; external saving; new developmentalism.

JEL Classification: F43; O11; O16; O19; O23; O24; O25.

While the old developmentalism was implemented successfully in Latin America during the 1940's until the 1960's, it proved to be inadequate in the 1970's in those countries where an import substitution strategy had achieved a solid industrialization. The old-developmentalism appeal weakened subsequently, meanwhile the 'conventional orthodoxy' started spreading over the world. Bresser Pereira's Globalization and Competition (Cambridge University Press, 2009) basically rejects the 'conventional orthodoxy' and the underlying idea that development performances in medium-income countries depend first of all on such institutions as property rights and contracts. Learning from history, the book proposes a renewed approach to developmentalism according to which the nation's international competitiveness is not regarded as a matter of markets only. According to the author, in the field of economic development the state is to be considered a strategic complement to markets, not an obstacle to markets efficiency. The "new developmen-

\footnotetext{
* Professor of Economics at the Université Paris 13. Researcher at CEPN. E-mail: Asensio.angel@ univ-paris13.fr. Submitted: May 2009; Aproved: July 2009.
} 
talism" therefore aims to create numerous opportunities for productive investments that, nowadays, are to be found in globalized markets. But it is a critical point of Bresser Pereira's argument to show that globalized finance seriously threatens the success of the development process in the medium-income countries if, instead of a well designed national development strategy, they follow the conventional orthodoxy. The paper starts with a general assessment of "Globalizaton and Competition", so that the arguments of the six chapters presented subsequently are made easy to understand as parts of the general purpose. It concludes with a few theoretical questions the book raises.

\section{AN OVERVIEW OF GLOBALIZATION AND COMPETITION}

Globalization and Competition is a book on economic development in emerging countries that have already successfully industrialized. Luiz Carlos Bresser-Pereira is concerned with why some countries perform well (like China, India, South Korea, Taiwan, Malaysia, Indonesia, and, more recently, Russia, Argentina, Vietnam...) while the others do not (like some medium-income countries in Latin America, the Middle East and sub-Saharan Africa), and with why some countries, like Brazil, perform well during certain periods but not in others. The explanation is basically found in the field of national development strategies.

Bresser-Pereira starts by criticizing the drawbacks of "conventional orthodoxy" or the "Washington consensus" that influenced numerous developing countries from the 1980s with the support of the US Treasury Department, the World Bank and the IMF (p. 84). Although the consensus has vanished, its macroeconomic aspect, "conventional orthodoxy", may still be considered the conceptual framework that rich nations have put forward in order to neutralize the competitive threat posed by medium-income countries with abundant and cheap labor forces, and in order to ensure the domination of their multinational companies. Although its discourse is favorable to free competition and balanced public budgets, the "conventional orthodoxy" actually encourages a kind of populist economic policy (p. 24). As for fiscal policy, the aim is to allow for moderate public deficits, so that the "rentiers", who hold public debt securities, are enriched by high interest rates. Attractive interest rates are ensured with the help of the central bank, whose mission amounts to combating inflationary pressure. As for exchange rates, the aim is to allow capital inflows to overvalue the currency, on the pretexts that foreign saving will improve the rate of growth in the long run, and that the prices of imported commodities will fall in the short run as a result of the high value of the domestic currency. ${ }^{1}$ Although such populism harms the interests of emerging countries and

\footnotetext{
${ }^{1}$ Another significant cause of overvaluation, which is discussed below, arises in countries that are richly endowed with cheap natural resources (the "Dutch disease"). "Overvaluation" should be distinguished from the case of currency appreciation identified by Harrod, Balassa and Samuelson in countries where productivity gains in the competitive sector are higher than in other countries. The Harrod-Balassa-
} 
the interests of workers (including those in rich countries) who suffer from industrial dislocation and loss of job opportunities, it prevails because it serves the interests of elites in both rich and emerging countries (pp. 20-21).

Emerging countries therefore are urged to repudiate the policy prescriptions of "conventional orthodoxy" and to implement the strategy suggested by the "new developmentalism". Drafting an outline of this strategy is the book's main contribution to the theory of economic development. "New developmentalism" first of all recognizes the crucial importance of macroeconomic policy, which means that industrial policy, the spearhead of the "old developmentalism", is now of secondary importance (though not unimportant) for medium-income industrialized countries. Instead of a growth strategy relying on external finance, "new developmentalism" promotes growth strategies based on domestic finance, balanced public budgets, moderate interest rates and competition policies aimed at neutralizing the tendency of the exchange rate to over-appreciation.

Bresser-Pereira rejects the widespread belief that the globalization process has deprived nation states of room to maneuver: they have partially lost their autonomy, but, since this has been the outcome of increased international competition, their role has turned out to be more strategic (p. 17). The nation state therefore resumes its proper role at the core of economic analysis: not as the entrepreneurial state of the industrialization stage, but as the "capable state", that is, the state which relies on markets and private entrepreneurs as far as the growth process is concerned, but which also organizes the nation's collective action in line with the design of the national development strategy (p. 21).

Since the tendency of the exchange rate to over-appreciation (the main macroeconomic dysfunction, according to the author) is a major market failure, the main obstacle to economic growth is located on the aggregate demand side, especially on external demand insofar as it reduces opportunities for export-oriented investment. The false Keynesianism - actually a "populist" one - which teaches that every problem may be solved by means of increased expenditures is rejected.

The methodology of such a discourse had to break with that of neoclassical economics. The author adopts a historical-structuralist approach, inspired by classical political economy and Keynes's macroeconomics. He considers that economies are open systems that cannot be completely transformed into mathematical equations, but this does not prevent the building of economic models. While the ability of the market to allocate productive resources is recognized, Luiz Carlos Bresser-Pereira points out some important market failures and stresses the advantages of public action in terms of collective efficiency. ${ }^{2}$

Samuelson effect does not involve any prejudice to the competitive sector, whereas Bresser-Peirera is concerned with distortions to the exchange rate that may seriously damage the economy.

${ }^{2}$ According to the author, the global financial crisis of 2008 signifies the failure of the neoliberal doctrine and of neoclassical theory, since governments have been obliged to intervene strongly instead of waiting for self-regulation to work. He also emphasizes that macroeconomic policies often are designed pragmatically rather than dogmatically, and, in this case, look much more Keynesian than neoclassical (pp. 19-20). 
The book comprises six chapters. The first three chapters deal with the strategic role of nation states in national development in a globalized economy. The last three chapters deal more specifically with the overvaluation problem, its causes and the way to overcome it.

\section{THE ROLE OF NATION STATES IN THE GLOBALIZED ECONOMY}

The first chapter starts by introducing a distinction between trade globalization - an opportunity for those medium-income countries that seek to catch up with the rich ones - and financial globalization, which is disastrous inasmuch as it prevents medium-income countries from neutralizing the overvaluation of their currencies, thereby seriously harming their international competitiveness. It is by means of overvaluation that rich countries prevent emerging countries from realizing the full advantages of their abundant labor forces. Bresser-Pereira then attacks the central idea of "globalism", according to which, because of interdependences, nation states have lost their autonomy over economic policies. Advocates of this idea seem to ignore the fact that these interdependences result precisely from the competition of nations, and that, from this point of view, national performances are related to the type of growth strategy the state promotes (including the strategy of financial liberalization). The chapter studies the genesis of this idea from the 1970s; it also considers the "global governance" rhetoric of the 1990s, which spread to the main international institutions, both official and non-governmental, making it easy for the type of policies promoted by "conventional orthodoxy" to disseminate around the world. But the success story of the Latin American "developmentalist" countries between the 1950s and the 1970s and, more recently, the rapid growth in Asian countries show that the nation state matters. The author insists that these successes brought benefits to the rich countries as well, for high levels of activity in emerging countries offered them important market opportunities and stimulated their levels of investment and output, with the result that international competition is not necessarily to be considered a zero-sum game (p. 47).

\section{NATIONAL STRATEGIES AS INSTITUTIONS TURNED TOWARD ECONOMIC GROWTH}

In its second chapter, the book bases its reflections concerning national strategies on institutions. At the more general level of the discussion, a national strategy is defined as a set of laws, policies and agreements aimed at creating investment opportunities for the private sector. As a national strategy needs the support of all the social groups, the state must make sure that the social bargain is secure, especially as regards the sharing of productivity gains, so that social cohesion is preserved.

A national development strategy deals with both the supply side and the demand 
side. On the demand side, special attention is to be paid to the control of the exchange rate, by means, if needed, of capital inflow controls. ${ }^{3}$ On the supply side, the author considers successively the roles of the financial system, economic planning, industrial policy, investment in public equipment, health and education systems, science and technology policy and the reform of public administration and services. In contrast to conventional orthodoxy, he maintains that the role of institutions should not be reduced to the protection of private contracts and property rights: indeed, the key growth institution is a national development strategy. The author reminds us that the legal-constitutional state is the consequence rather than the cause of economic development, and that in China, for example, foreign companies have invested so much, not because property rights have been guaranteed (such a guarantee has been implemented only recently), but because there has been a national growth strategy designed to offer high expected profits to foreign investors (p. 65). Whereas the orthodox literature systematically stresses the conflict of interest between the state and private agents, this chapter adopts an approach that focuses on their complementarity and mutual advantage, in the way inspired by Polanyi.

\section{NEW DEVELOPMENTALISM VS CONVENTIONAL ORTHODOXY}

Chapter 3 provides a stimulating discussion on national strategies and the role of the state during the twentieth century. The "old developmentalism" of the period 1930-1970 was a strategy based on the protection of the newly industrialized sectors and on import substitution. It reached its limits when the level of economies of scale in the industrial sector introduced negative effects into the growth process, ${ }^{4}$ thereby pushing the economy to become outward-looking. The exhaustion of the old developmentalist model then reinforced the neoliberal doctrine, while the major debt crisis of the 1980s increased the political influence of the rich countries. Hence, the industrialized emerging countries where the Washington consensus recommendations had been implemented, notably those of Latin America, experienced a reduced growth rate, in contrast to the rapid growth of Asian economies, which had maintained autonomous national growth strategies (p. 58). ${ }^{5}$

Echoing the research he undertook with Yoshiaki Nakano, the author then specifies the outlines of "new developmentalism", a third discourse lying between

\footnotetext{
${ }^{3}$ The point is not discussed further here, as it is the main topic of the last three chapters.

${ }^{4}$ In the Brazil of the 1970s, the exploitation of returns to scale resulted in both an increase in the capital-labor ratio and an increase in income inequality, so that luxury goods industries could develop (the "model of industrial under-development", p. 73).

${ }^{5}$ In this chapter, the author reminds us that South Korea, Indonesia, Malaysia and Thailand experimented with a growth strategy that relied on external financing, which produced the financial crisis of 1997; those countries then promptly went back to autonomous growth financing.
} 
the one proposed by the "bureaucratic populist left" 6 on the one hand and "conventional orthodoxy" on the other. New developmentalism rests first and foremost on a strong state, along with the reform of public administration and safe public finance, so that the authorities have the capacity to support effectively a national strategy for growth. Social cohesion also is considered a condition of rapid growth, because it induces the support of every social group and because a fair sharing of productivity gains allows workers' wages to feed aggregate demand. As for industrial policy, the primary objective should be to encourage and support firms whose competitiveness is close to international standards, especially those whose products have high added value, so that international markets allow them to exploit deeply their high returns to scale. This encourages the opening of the economy and the renunciation of protectionism, except if the "Dutch disease" is to be neutralized (see below). However, openness does not mean liberalization without any control; the process of openness should be accompanied by pragmatic bargaining at the World Trade Organization.

The objective of such a strategy is to raise the investment ratio, financing it with domestic saving ${ }^{7}$ rather than external saving, so that the pernicious effects of external saving are avoided (overvaluation of the exchange rate, substitution of foreign for domestic savings, financial instability, low growth rates). The rejection of an open capital account is clearly part of the strategy. New developmentalism also seeks to assign a wide range of objectives to monetary policy, beside the control of inflation. It recommends maintaining short-term interest rates at a low level, so that economic activities may be financed with moderate long-term interest rates. Exchange-rate management is also recommended in order to avoid an overvaluation of the currency (even by means of capital inflow controls if need be).

The end of the chapter offers an interesting empirical illustration of the gap between the growth rate of those countries that implemented the conventional orthodoxy and that of countries with autonomous strategies. It also provides an empirical study of the main factors making for growth that new developmentalism has identified (limited public deficits, a balanced current account — which means a competitive (that is, not overvalued) exchange rate - and a high investment-output ratio).

\section{CURRENCY OVERVALUATION}

Chapter 4 opens with a discussion on the tendency of the exchange rate to overvaluation. Of the key factors of economic growth, a competitive exchange rate

\footnotetext{
${ }^{6}$ The Left's populism is associated with budget deficits, unsustainable debt and inflation.

${ }^{7}$ The argument sometimes is in favor of financing national investment with public saving (pp. 79, 89-90), which requires a budget surplus, while at the same time "new developmentalism" seems to be in favor of balanced budgets (pp. 82-83, 91) or of budget deficits (Table p. 89, second sentence of the second paragraph, p. 90).
} 
is considered the most important. Although growth theory neglected it for a long time, "the exchange rate indeed is a powerful factor not only to exports and imports, but also to wages, consumption, investments and saving as well” (p. 105). The author then presents in parallel the literature on the relation between the exchange rate and economic growth, and his own views on the negative effects of overvaluation and on the importance of having a "competitive exchange rate". The competitive exchange rate is defined as the rate that does not dissuade those firms which use the best technology (supply-side condition) from investing and producing for international markets (demand-side condition) (p. 114). In case of a currency overvaluation caused by the inflow of foreign savings or by the Dutch disease, the concomitant overvaluation of real wages (due to the reduced price, in domestic money, of imported goods) and artificially inflated-related consumption (since the workers' propensity to consume is relatively high, which increases the average propensity) will have pernicious effects in so far as the average saving propensity and the investment rate will be insufficient to assure catching up growth. Besides, as suggested at the end of the chapter, the cocktail of currency overvaluation and external saving leads to a balance of payment crisis.

\section{DUTCH DISEASE}

Chapter 5 discusses one the main causes of currency overvaluation: the "Dutch disease" or the "natural resources curse". This is a recurrent currency overvaluation which is due to the trade surpluses that result from having abundant natural resources. Cheap resources allow for high profits and highly competitive commodities in international markets combined with the overvaluation of the exchange rate. Such overvaluation is indicated by the fact that in other tradable industries business enterprises utilizing state-of-the-art technology will not be viable economically. It is an advantage for a country to possess such abundant resources, but the overvaluation of the national currency severely harms the economy. At the end of the chapter the concept of the "Dutch disease" is extended to the case of countries that dispose of abundant and cheap labor, such as China. The Dutch disease will occur if the wage spread (the difference between the average salaries of engineers and the wages of laborers) in the country is substantially higher than in rich countries. ${ }^{8}$ Accordingly, the author emphasizes how managing the exchange rate will make it possible to overcome these difficulties.

In opposition to those explanations that emphasize the role of corruption and

\footnotetext{
${ }^{8}$ The argument in this case is that the currency overvaluation, which is due to the strong performance of those sectors intensively using low-cost labor, prevents high value-added sectors from developing too, especially when the workers' remuneration is relatively high in the high-technology sectors (which presupposes that there is greater remuneration inequality than in the rich countries, p. 148). As a consequence, the labor force tends to remain in the low-technology sectors, instead of migrating to high value-added activities and achieving higher skills.
} 
of political and institutional weakness, Bresser-Pereira underlines the economic source of the problem. Yet he does not deny that the other factors can make the problem more serious. The Dutch disease is interpreted in terms of market failure, as a result of the Ricardian rent of the sector using the abundant natural resource intensively, which imposes negative externalities on the other sectors of the economy (p. 126). In support of his thesis, Bresser-Pereira maintains that "since the second world war, Asian non-oil countries have grown more than Latin America non-oil countries, and the latter have grown more than oil-exporting countries. African countries richly endowed with mining have had almost no growth" (p. 135).

The proper functioning of the development process requires the tendency of the exchange rate to over-appreciation to be neutralized; only on this condition is the market "capable of playing its role in the allocation of resources and of encouraging investment and innovation" (p. 127). The neutralization mechanism is based on a tax on sales and exports in the sector which exploits the abundant resources. The tax must be equal to the difference between the current account equilibrium exchange rate and the "industrial equilibrium exchange rate" (the latter corresponds to a competitive rate as defined above ${ }^{9}$ ) so as to shift the supply curve of the commodity upwards. Then, the tax revenues should be directed to a fund dedicated to foreign investment, so that the tendency to exchange-rate overvaluation is effectively offset. Although the principle of such a tax is simple, the author insists that it could be difficult to implement. First, exporters of those sectors that use abundant resources intensively may not be aware that the currency depreciation is increasing their income in the same proportion as the tax they pay, which may lead them to oppose the tax. In the same spirit, consumers may resist the tax as well because of the negative effects of a currency depreciation on the purchasing power of wages. Moreover, the temporary inflationary effect resulting from the increase in the prices of imported goods may produce discontent, and, in addition, it may be very tempting to divert the tax revenues to other objectives.

\section{NEGATIVE EFFECTS OF EXTERNAL SAVING}

The second important cause of currency overvaluation in developing countries is their willingness to attract capital inflows. It may seem paradoxical to consider foreign capital inflows as an obstacle to economic development. The literature on the subject mainly focuses on the difficulties related to the volatility of capital inflows, or on the asymmetry between the rich countries, which are allowed to run up debt in their own currencies, and the emerging countries, which are not; but, in his Chapter 6 (written with Paulo Gala), the author considers other important

\footnotetext{
${ }^{9}$ Just as the competitive exchange rate differs according to the type of industry, so the tax should be differentiated as well. It should also be adjustable in case of a change in the magnitude of the currency overvaluation.
} 
negative effects. Indeed, when the current account of a country with net capital inflows is in deficit (foreign savings), even in the absence of any "Dutch disease", an overvaluation of the currency will occur (as, according to the author, the equilibrium exchange rate in this case should balance the current account, p. 160). As discussed in Chapter 4, as a consequence of an increase in consumption the appreciation of the currency will increase the workers' purchasing power, and, thereby, the average propensity to consume (at the expense of the propensity to save). In addition, at the same time the expected return on productive investment falls inasmuch as the currency appreciation weakens the competitiveness of firms in international markets (as well as in the domestic market). In consequence, additional consumption will be partially served by additional imports; instead of an increase in the investment rate we will experience the substitution of foreign for domestic savings. ${ }^{10}$

The second half of the chapter is an empirical assessment of the substitution of internal saving by external saving. The study is largely documented, notably in the insert on pages 167-169, and, as concerns the case of Brazil, in the subsequent pages (pp. 169-172). The author estimates the substitution effect at around 50 percent in normal circumstances, but the figure may vary significantly (by 132 percent in Brazil over the period 1994-1999, for example) according to the expected return on productive investment and the growth of aggregate demand.

The conclusion that emerges from the chapter is that, except in especially favorable circumstances (countries that already grow rapidly and have high expected returns on investment; see also p. 50), growth strategies with external financing have significant pernicious effects and slow economic growth in emerging countries. This chapter finally corroborates the proposition that "capital is made at home" (p. 118).

\section{FINAL DISCUSSION}

Globalization and Competition deals with many topics and handles rich material. It provides answers to numerous questions in the field of economic development, and sometimes suggests new questions for the reader. If we disregard for the moment the "Dutch disease" phenomenon, the issue arises of the tension between the author's definition of the equilibrium exchange rate (which, in this case, would correspond to a balanced current account, and, ideally, to zero or near-zero external debt, that is, to approximately a balanced trade account) and the importance he attaches to exports in the new developmentalist strategy. If imports and exports are supposed to grow together, in such a way that the country loses in the domestic

\footnotetext{
${ }^{10}$ Furthermore, the author states that profits also may decrease because of real wages increases (p. $160)$; but there is no direct relation between those variables in the case under discussion, as real wage increases result from a decrease of the price of imports, not from a decrease of profits.
} 
market the demand it incurs from abroad, there would no be net advantage in terms of aggregate demand. It is, however, in the spirit of Bresser-Pereira's book to say that the export-led character of the growth strategy is aimed at allowing firms in performing sectors to exploit deeply economies of scale arising from access to foreign markets. It is, therefore, the higher purchasing power per head which feeds the growth process, even though, simultaneously, increased imports allow foreign partners to obtain a similar advantage.

If we still disregard provisionally the "Dutch disease", a second issue arises, concerning the equilibrium exchange rate itself. The statement that the current-account equilibrium position is zero is theoretically and empirically fragile. In the mainstream literature, it is based on an unrealistic formal representation of the economic system, within which individuals choose their portfolio compositions by means of intertemporal optimal decisions. A zero current account from this perspective indicates that there are no international capital flows, that is, holders have stabilized the stock of the different types of assets in their portfolios. However, empirically, current accounts can hardly be considered stationary, which is not amazing at all, since, theoretically, this would require the existence a complete market structure, which is pure imagination in so far as future events are fundamentally uncertain. In the real world, individuals are well aware that long-term expectations based on current information might be systematically invalidated in the future. Therefore, in the absence of any reliable anchor for long-term expectations, financial decisions result essentially and continuously from individuals' changing intuitions (as Keynes suggested with his "animal spirits" metaphor), which allows us to understand why no tendency toward asset stocks stabilization emerges in the data. If, as a consequence, the equilibrium exchange rate has no anchor, then net inflows/outflows do not necessarily indicate a currency over/undervaluation. This is actually what Luiz Carlos Bresser-Pereira implicitly recognizes when he notices that, in certain circumstances, external saving may be beneficial to economic development. The right discussion henceforth is about the conditions under which external saving is beneficial, as opportunely illustrated in the book. ${ }^{11}$

As for the central issue, the tendency of the exchange rate to over-appreciation, however much it is due to excessive inflows of foreign capital or to the "Dutch disease", one may wonder why the theoretical discussion does not consider the possibility that firms might offset the high value of money (in terms of foreign currency) by reducing in due proportion their supply price (in terms of domestic money), instead of assuming that firms passively absorb the damage caused by the overvaluation of money. Such price-setting practices are well documented empirically and may weaken considerably the impact of nominal exchange-rate variations

\footnotetext{
${ }^{11}$ The author's estimate of the substitution of internal saving by external saving suggests that, in normal circumstances, external saving contributes positively to investment and growth. Although the author recognizes this point (p. 163), the subsequent discussion is concerned only with negative effects.
} 
on the real exchange rate, as attested, for example, in Brazil between 2002 and 2005 (p. 172).

Reading new books always entails new reflections, improves our understanding of observed phenomena and allows for further developments. Globalization and Competition is full of stimulating ideas, empirical illustrations and references to both the recent literature and the history of economic development. It is therefore a valuable tool for specialists of the field (brilliantly put into perspective in the foreword by Robert Boyer), and, for non-specialists, is a stimulating explanation of essential issues on economic growth and development in emerging countries. The exposition does not have the mathematical rigor that mainstream economics is particularly attached to, but it is precisely the virtue of the book that the artificial worlds which result from the desire to formalize at all costs make way in the author's penetrating mind for the real mechanisms of the global economy. 